\title{
The Secretary's Corner
}

\author{
By G. F. LEDINGHAM
}

The annual meeting held October 29, 1.955, closes the books on the thirteenth year of publication for the Blue Jay. This past year has seen more pages in our magazine, pictures on our front and back covers, and other attractive features instituted by our editor, Mr. L. T. Carmichael. We would like to continue these features and add others, but first. we must get more subscriptions in for next year so we can plan our budget.

The treasurer's report read at the meeting shows an income of $\$ 2,063.26$. In addition to the regular memberships of one dollar per year this figure includes a few dollars for back copies of 1954 issues and $\$ 13.76$ interest. The expenses during the year were the highest in our history-\$2202.59. This leaves us with a financial loss of $\$ 139.33$ for the past year. Our net worth which was $\$ 1,047.95$ at the time of our annual meeting in Yorkton on October 23,1954 , is now $\$ 908.62$, a decrease of $\$ 139.33$.

Those most active in sending in memberships during the past year have been Dr. S. Houston, Yorkton and Saskatoon; A. Ward, Swift Current; Mrs. J. Hubbard, Grenfell; Mrs. O. L. Wolters, Tolland, Alberta; J. Shaver, Regina; C. Shaw, Yorkton; F. Baines, Saltcoats; E. Symons, Rocanville; H. C. Weaver, Lloydminster; F. Bard, Sr., Edmonton; Rev. T. Beveridge, Pathlow; Mrs. R. Paling, Lashburn; A. E. Faulkner, Doonside; J. Penny, Dysart; and the Prince Albert Natural History Society. As treasurer, I wish to thank these and all others who have sent in money to the Saskatchewan Natural History Society.

Special credit should be given to Mrs. Orman and Mrs. Hawkins who teach at Antler for they put the Blue Jay in the home of every child in their school. The Homemakers Clubs at Dubuc and Stockholm deserve special credit too for giving the Blue Jay to each school in their district. There is good evidence that the Blue Jay is appreciated by teachers and pupils alike. It should be available to every school child in Saskatchewan. We are giving a $10 \%$ school discount to any person or group who wishes to give the Blue Jay to schools or to school children.

The number of larger school units supporting the Blue Jay has increased with the addition of the Swift Current. School Unit which puts our magazine in 50 more schools. The school units of Nipawin, Herbert, Yorkton, Sturgis and Regina City have supported us for two years. The school units of Wilkie, Milestone and Weyburn have supported us for three years. We are grateful to those who have approached these school units and persuaded them to subscribe. Does your school unit subscribe to the Blue Jay? Remember, there is a $10 \%$ discount for schools.

Please send in your renewal now or remember to send it early in 1956. Our address labels must be made up before the end of February. Please help our new secretary by renewing promptly. He is Mr. E. L. Fox, 1053 Gladmer Park, Regina, Sask. 


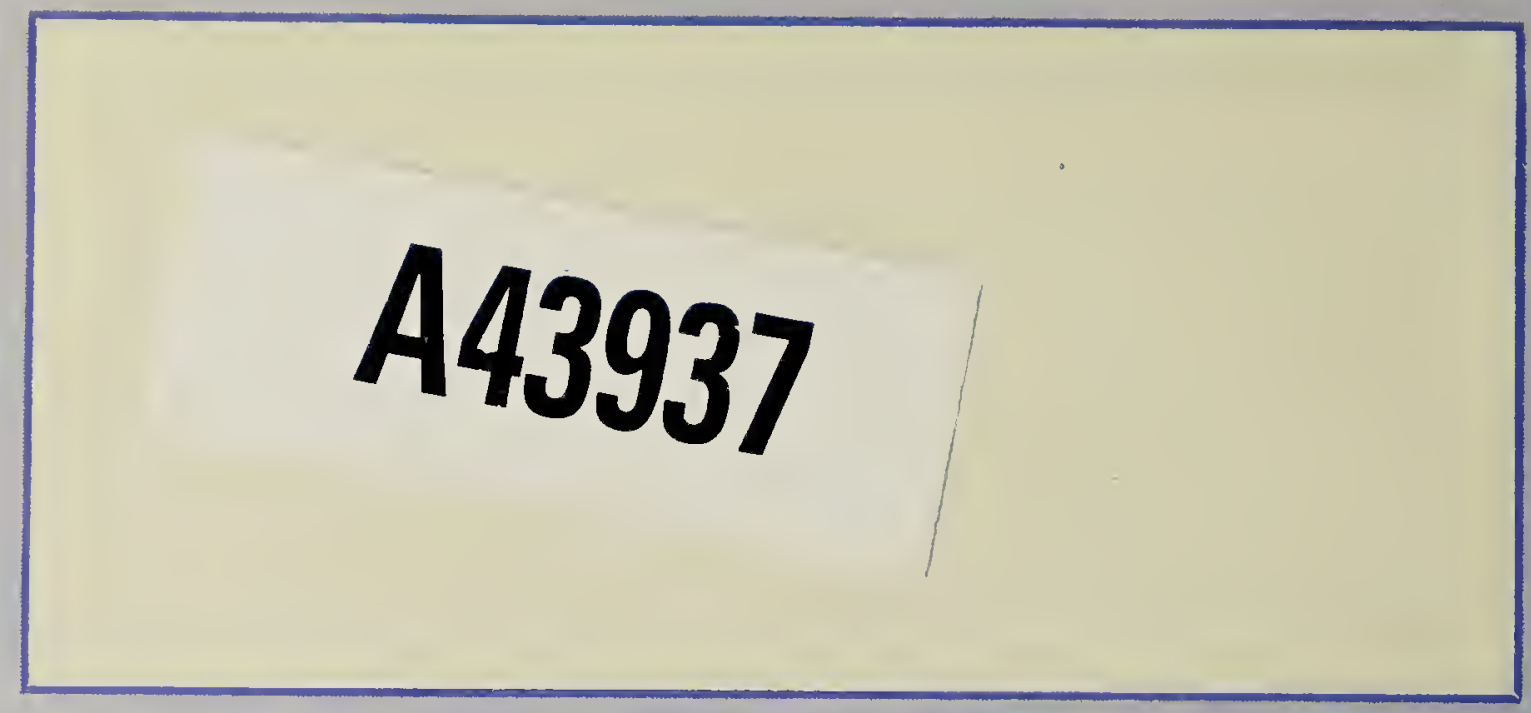

Authorized as Second Class Mail, Post Office Dept., Ottawa Return Postage Guaranteed

Published quarterly by

THE SASKATCHEWAN NATURAL HISTORY SOCIETY

Edited by Lloyd T. Carmichael

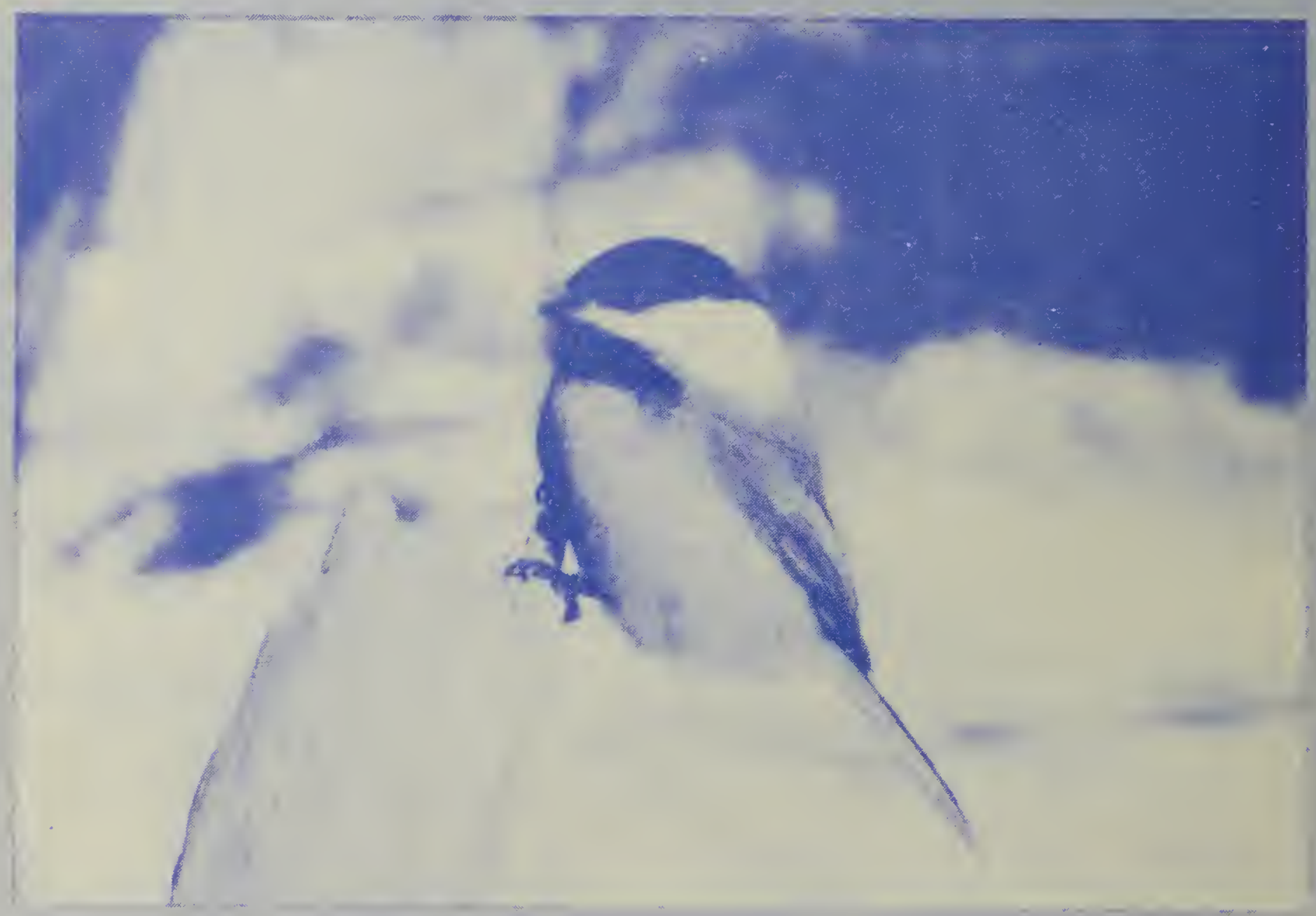

Photo by Doug Gilroy

SEND ALL SUBSCRIPTIONS, RENEWALS AND ACCOUNTS TO E.L. Fox 1053 Gladmer Park Regina

MAIL ALL MATERIAL FOR PUBLICATION TO

Dr. George F. Ledingham

2335 Athol St., Regina 